\title{
OLHARES COMUNICACIONAIS: O MAPEAMENTO DAS PRODUCÕES ACADÊMICAS DA ÁREA REALIZADAS COM O FOMENTO DA FAPESP A PESQUISADORES DA ECA/USP E DA UNIVERSIDADE METODISTA DE SÃO PAULO*
}

\author{
Rodrigo GABRIOTI* \\ Universidade Metodista de São Paulo, São Paulo, SP
}

\section{RESUMO}

Como a edição 2016 do Pensacom celebra datas de dois Programas de Pós-Graduação em Comunicação, decidimos verificar como seus pesquisadores têm promovido a construção da Área e dela participado. Pelos Programas da ECA/USP, que celebra 50 anos e da Universidade Metodista de São Paulo cujo Doutorado completa 20 anos, buscamos pesquisas e pesquisadores que receberam fomento da FAPESP. Adotamos a pesquisa documental com a Biblioteca Virtual (BV) da FAPESP para chegar às realizações com esse apoio financeiro. Da pesquisa bibliográfica, trazemos a noção de espírito científico, de Gastón Bachelard, por acreditarmos que, a partir do ambiente acadêmico, é que as contribuições devem florescer. Esses momentuns de pesquisa equivalem ao conceito das vivências, postulado por Dilthey (2010). Mesmo com alguns anos de diferença entre um Programa e o outro, percebe-se em ambos a preocupação em formar o pesquisador e estabelecer o diálogo extramuros.

Palavras-chave: Comunicação; ECA/USP; Fapesp; Pesquisa; Universidade Metodista de São Paulo.

* Trabalho apresentado no GT Pensamento Comunicacional, do PENSACOM BRASIL 2016.

** Doutorando do Curso de Pós-Graduação em Comunicação da Universidade Metodista de São Paulo. Jornalista e Professor, email: rgabrioti@hotmail.com. 
Este artigo nasceu da feliz sincronicidade entre a pesquisa que desenvolvemos para nosso doutoramento e um dos principais objetivos deste Pensacom 2016. Já havendo participado de edições anteriores, ao saber que, neste ano, a proposta era debater o pensamento comunicacional brasileiro, devido à celebração de algumas datas importantes de Escolas e Instituições que se dedicam, por meio da pesquisa, ao amadurecimento da Área da Comunicação, propusemos uma junção que resultou nesta análise comparativa.

Tomamos, por base, as efemérides de 50 anos da ECA/USP e os 20 anos do Doutorado em Comunicação da Universidade Metodista de São Paulo sob um novo prisma: saber como tem sido a produtividade de seus pesquisadores - docentes e discentes - que buscaram o fomento da Fundação de Amparo à Pesquisa do Estado de São Paulo (FAPESP) como fonte de viabilização de seus projetos. A ideia faz sentido porque nossa pesquisa de Doutorado, em desenvolvimento, no Programa de Pós-Graduação em Comunicação da Universidade Metodista de São Paulo, sob a orientação do Prof. Dr. José Marques de Melo, se debruça exatamente sobre como a Área vem sendo construída, cartograficamente, dos anos 90 para cá por intermédio dos estudos realizados com o apoio financeiro da FAPESP registrando inclusive a primeira passagem de século nos estudos em Comunicação.

Levando em consideração as duas universidades, recorremos então à pesquisa documental, tendo, como amostra, o acervo da Biblioteca Virtual da FAPESP. Utilizamos como método, a opção de busca no próprio site da Fundação, inserindo as expressões "ECA/USP" e "Universidade Metodista de São Paulo" na Tabela de Áreas da Fundação, mais precisamente, na Comunicação. Da ECA/USP, apareceram 44 resultados entre os anos de 1995 e 2016. Já da Universidade Metodista foram 48 entre os anos de 1998 e 2016.

Observar a produtividade acadêmica a partir do fomento constitui um pressuposto que consideramos convergente ao que defende Dilthey (2010) sobre o sistema cultural. Para ele, um sistema cultural envolve regras de existência, posições, valores e finalidades que representam uma significação própria resultante da relação da sociedade com sua história, pois, assim, se pode entender os indivíduos de acordo com seu tempo e seu lugar. Um perfeito entendimento para o que é fomento, isto é, a possibilidade concedida de maior dedicação à pesquisa que visa compreender esses estratos de tempo e lugar como uma das fontes legitimadoras de nossa Área. Considera Dilthey (2010, p.93) que "[...] uma decisão só se torna possível por meio da ponderação sobre a relação entre as representações de metas com a realidade e os meios dados na realidade para a realização dessas representações". Consideramos que nesta fala de Dilthey reside o essencial do ato de pesquisar. 
Pesquisa constitui atividade tardia na Comunicação. Marques de Melo (2008) lembra-nos de que se trata de um campo jovem do conhecimento já que sua constelação acadêmica irrompeu em meados do século XX. Os primeiros centros de pesquisa dentro das universidades datam dos anos 1960, com o pioneirismo do Instituto de Ciências da Informação (ICINFORM), fundado por Luiz Beltrão, em Recife (PE). Só nos anos 1970, a pesquisa vai constituir atividade social das universidades. Os primeiros cursos brasileiros de pós-graduação em Comunicação aparecem na USP, na UFRJ, na UNB, na PUC-SP e na Metodista-SP. Dessas cinco instituições, duas fazem parte da amostra de análise deste artigo.

A ECA/USP iniciou suas atividades em 1967. Chamava-se Escola de Comunicações Culturais e formavam seu corpo docente especialistas de diversas áreas do saber voltados ao ensino e à pesquisa na nova Área do conhecimento em busca de consolidação, no caso, a Comunicação. No ano de 1969, seus cursos de Mestrado ede Doutorado começaram a funcionar. $\mathrm{Na}$ Comunicação, o Mestrado começou em 8 de janeiro de 1972, como pioneiro no Brasil ao passo que o Doutorado deu sua largada oito 8 anos depois, mais precisamente em maio de 1980. Ao final desta década, a ECA já era responsável por $48 \%$ da pesquisa acadêmica do Brasil. Fato que atraiu a atenção de agências de fomento, inclusive da própria FAPESP, que passaram a reconhecer a Área da Comunicação com pesquisa autônoma, migrando assim de seu conceito como "especialidade da Sociologia".

Desde 2006, o Programa de Pós-Graduação em Comunicação da ECA/ USP trabalha com três Áreas de Concentração: Teoria e Pesquisa em Comunicação; Estudos dos Meios e da Produção Mediática e Interfaces Sociais da Comunicação. Suas linhas de pesquisa são: Epistemologia, Teoria e Metodologia da Comunicação; Linguagens e Estéticas da Comunicação; Comunicação e Ambiências em Redes Digitais; Informação e Mediações nas Práticas Sociais; Consumo e Usos Midiáticos nas Práticas Sociais; Comunicação, Cultura e Cidadania; Políticas e Estratégias de Comunicação e Comunicação e Educação.

$\mathrm{Na}$ Universidade Metodista, o curso de Mestrado foi implantado em 1978; já o Programa de Doutorado, em 1995. Juntos, têm mais de 590 dissertações produzidas e 130 teses defendidas. Atualmente tem sua Área de Concentração em processos comunicacionais com três linhas de pesquisa: Comunicação Midiática, Processos e Práticas Culturais; Comunicação Institucional e Mercadológica; Comunicação Comunitária, Territórios de Cidadania e Desenvolvimento Social. A primeira envolve os estudos sobre veículos de comunicação de massa e comunicação alternativa. Na segunda, encontram-se os estudos sobre discursos organizacionais e relações de consume; e a terceira enfatiza as inovações tecnológicas, especialmente, a TV Digital. 
De acordo com a Avaliação Trienal 2013, que sofreu uma reconsideração a pedido dos Programas, conforme constava no site da CAPES, em julho de 2016, o Programa de Ciências da Comunicação da USP possui nota 5. Desse modo, o Programa torna-se referência nacional com desempenho muito bom em quatro de cinco quesitos da ficha de avaliação, com destaque para o corpo discente e para a produção intelectual. Com nota 4, que significa desempenho bom, aparece a Universidade Metodista. Isso significa que três em cada cinco quesitos estão bem aprovados, entre eles, também o corpo discente e a produção intelectual.

Tais desempenhos constituem resultados de uma construção de longo prazo em busca de legitimação e de maturidade. Avanços que vêm desde a gênese das instituições. Em Teoria e Metodologia da Comunicação - Tendências do Século XXI, Marques de Melo (2014) remonta às raízes do pensamento uspiano cuja inspiração foi o tradicional sistema europeu. De acordo com o autor, o fenômeno da Comunicação impõe-se apenas nos anos 1960, com a Escola de Comunicações Culturais, já mencionada anteriormente. Essa largada é pouco menos de três décadas depois da fundação da USP, ocorrida em 1934. Apesar dessa diferença de tempo, Marques de Melo (2014) recorda Ernesto de Souza Campos que diz em uma de suas obras sobre a história da Universidade de São Paulo, publicada em 1954, que a instituição possuía ampla infraestrutura comunicacional com rádio, editora, filmoteca, discoteca, biblioteca e um serviço de extensão para tornar eficiente a propagação do conhecimento entre as unidades de ensino e de pesquisa. Entretanto, Marques de Melo (2014) aponta que a Escola de Comunicações Culturais sofreu nessa sua denominação um preconceito próprio de seus criadores. Segundo o autor (2014, pp. 195-196), “[...] a Comunicação demorou a ser atividade cognitiva dotada de autonomia na Universidade de São Paulo. Apesar de reconhecido como campo social pelos seus fundadores, o campo acadêmico demorou trinta anos para conquistar legitimidade".

Assíduo pesquisador da História de nossa Área, no artigo "O Grupo Comunicacional de São Bernardo: ideias hegemônicas e perfil sociográfico", Marques de Melo (1999) trata da gênese da Área da Comunicação na Universidade Metodista de São Paulo. A instituição surgiu como Federação de Escolas Superiores do ABC, mantida pelo Instituto Metodista de Ensino Superior. Instalado em São Bernardo do Campo (SP), ocupava uma área geográfica de relevância, sobretudo, nos anos da Ditadura Militar: o ABC Paulista. Lá, o Partido dos Trabalhadores (PT) deu seus primeiros passos através do Movimento Sindical e as igrejas vivenciaram práticas pastorais inspiradas na Teologia da Libertação. Esses fatos fizeram a imprensa, à época, considerar a cidade como "República de São Bernardo". 
Nessa República, a Comunicação teve espaço fundamental e contributivo à Metodista, pois, nos anos 1970, o Reverendo Dr. B.P. Bittencourt convenceu a instituição a criar bases para o desenvolvimento de uma universidade. Assim surgia um Centro de Pós-Graduação no estilo das Graduate Schools dos EUA com a finalidade de desenvolver pesquisas avançadas de formar lideranças acadêmicas. Contrataram-se doutores e livres docentes, reforçaram-se os acervos bibliográficos e ofereceram-se as adequadas condições de trabalho. Tais decisões deram início à legitimação acadêmica da instituição cuja estrutura começou pelas Ciências da Comunicação.

Além das atividades de pesquisa, um marco importante consistiu na criação da Revista Comunicação \& Sociedade que segue publicada até hoje. Tudo isso foifortalecendo a identidade comunicacional do Grupo de São Bernardo, considerado por Marques de Melo (1999) como um grupo de perfil intergeracional, que envolvia catedráticos reconhecidos por sua maturidade e jovens pesquisadores. Os primeiros catedráticos na Metodista foram o próprio José Marques de Melo além de Gaudêncio Torquato e Cândido Teobaldo Andrade.

Quando começou a funcionar, no fim dos anos 1970, o Mestrado apregoava liberdade de cátedra, com a expectativa de criar uma cultura com novos ideais, novos paradigmas e novas pesquisas. A intenção era direcioná-los aos fenômenos da comunicação não-hegemônica, ao universo midiático, à comunicação dialógica no ambiente organizacional, à indústria cultural e à comunicação popular,aos meios e mensagens, aos produtores e receptores, à mídia regional e à comunicação eclesial. Até os anos 1990, os estudantes eram mais da região do ABC e da Capital, porém, a adesão de alunos de todas as regiões brasileiras e de países latino-americanos aumentou e mudou esse perfil macrorregional.

Nesse ambiente, uma série de fatores, como pesquisadores trabalhando em regime integral de dedicação ao Programa, um prédio exclusivo para abrigar o curso e o compromisso de gerar um fluxo de conhecimento que abastecesse a sociedade com publicações e comunicações em congressos científicos foram, segundo Marques de Melo (1999), um conclave para o desenvolvimento do curso de Doutorado em Comunicação na Universidade Metodista de São Paulo.

\section{ESTRUTURAS E SUJEITOS: O ESPÍRITO CIENTÍFICO NA LEGITIMAÇÃO DA HISTÓRIA DA COMUNICAÇÃO}

Até aqui, focalizamos as bases estruturais dos programas escolhidos como amostra de análise deste artigo. Nós as entendemos como fundamentais para o desenvolvimento da pesquisa, já que por meio delas, se viabiliza a 
compreensão da História em torno de uma área de interesse. Nessa direção, Dilthey (2010, p.253) afirma: "Onde quer que a vida tenha passado e tenha ganho a compreensão, há história. E onde há história, a significação se faz presente em sua multiplicidade". Desse modo, segundo o próprio autor diz, estabelece-se uma hermenêutica da organização sistemática, que pode manifestar-se sob várias formas. Uma delas, que trabalhamos neste artigo, são as pesquisas com o foment da FAPESP, ou seja, pesquisar com o apoio das agências financiadoras constitui uma forma de hermenêutica.

Porém as estruturas não fazem parte dessa hermenêutica sozinhas. Elas também precisam dos sujeitos, fundamentais para estabelecer o olhar que dirige o sentido da pesquisa. Por isso, trabalhamos com o conceito central) do espírito científico, de Bachelard (1995). Esse espírito depende da realidade, mas se separa do homem comum. O autor (1995) diz que ninguém se arroga o espírito científico se não tiver segurança e se não reconstruir o próprio saber, o que necessita de eixos racionais para ocorrer. Nessa direção, o autor (1995, p.18) afirma:

O espírito científico proíbe que tenhamos uma opinião sobre questões que não compreendemos, sobre questões que não sabemos formular com clareza. Em primeiro lugar, é preciso saber formular problemas. E, digam o que disserem, na vida científica os problemas não se formulam de modo espontâneo. É justamente esse sentido do problema que caracteriza o verdadeiro espírito científico. Para o espírito científico, todo conhecimento é resposta a uma pergunta. Se não há pergunta, não pode haver conhecimento científico. Nada é evidente. Nada é gratuito. Tudo é construído.

Para tanto, o primeiro passo é sair da generalidade, que imobiliza o pensamento, como reforça o autor. Um caminho para isso, apontado por Bachelard (1995), é a reconstrução, a cada momento, dos problemas particulares sem a preocupação com a ordem histórica dos fatos. É que, como ele mesmo diz, todo problema científico é, inicialmente, um obstáculo não no sentido de impedimento a uma realização, mas sim, da perspectiva do ato de conhecer. Embora haja os interesses particulares de cada um, os pesquisadores estão nas instituições a serviço desses pressupostos do obstáculo, pois, considera Bachelard (1995, p.17), que “[...] o real nunca é 'o que se poderia achar' mas é sempre o que se deveria ter pensado". O autor arremata afirmando que todo espírito científico tem de manter uma luta constante contra imagens, analogias e metáforas. A fórmula contra ela é a experiência racional, determinada pela formulação do problema, procedimento característico do espírito científico. 
Isso determina que jamais o conhecimento fique sem sistema porque o espírito empresta suas categorias à realidade. Quando tal processo ocorre, a descrição tende a fechar-se em um método de construção que se apresente como necessariamente acabado, considera Bachelard (2004). Discordamos desse preceito, pois, sabemos que um conhecimento não se esgota em uma pesquisa já realizada. O que buscamos ao comparar o que os pesquisadores da ECA/USP e da Universidade Metodista de São Paulo produziram, com o apoio da FAPESP, é identificar o que se tem produzido em estudos de Comunicação bem como a contribuição desses sujeitos de pesquisa tanto para a legitimação da Área quanto para o amadurecimento de seus programas. Embora tenhamos apresentado esta pequena discordância de Bachelard (2004), voltamos a concordar com ele quando (2004, p.19):

Essa inflexão do espírito, em direção ao passado, para responder à solicitação de um real inesgotável constitui o elemento dinâmico do conhecimento. Ao reviver o impulso é que se pode escrever, digamos assim, a equação diferencial do movimento epistemológico. A retificação parece-nos não um simples retorno a uma experiência malograda que pode ser corrigida por uma atenção mais forte e mais competente, mas sim o princípio fundamental que sustenta e dirige o conhecimento e o instiga sem cessar a novas conquistas. (BACHELARD, 2004, p.19)

Desse modo, vimos traçando essa equação diferencial do movimento epistemológico, que nos dá pistas sobre o que se sendo produzindo nos programas analisados. Não se trata, realmente, de saber se foram experiências malogradas. O propósito é seguir o que diz Dilthey (2010, p.312) sobre o vivenciar...

[...] das grandes formas da cultura e de sua organização exterior, de seu desenvolvimento, de sua atuação recíproca em uma época, na estrutura da sociedade, tal como ela existe no interior de um período demarcável, no interior dos momentos desse período, momentos que produzem paulatinamente transformações nesse período.

\section{PESQUISAS NA ECA/USP}

Realizaram-se, com o apoio da FAPESP, 44 atividades de pesquisa realizadas na ECA/USP. Levamos, em consideração, as seguintes categorias de análise: Tempo de Vigência do Fomento, Orientadores, Mestrado, Doutorado, Auxílios à Pesquisa, Bibliografia, Temas, Programas FAPESP, Pesquisadores Beneficiados, Pesquisador Visitante, Metodologias, Pós-Doutorado, Iniciação Científica e Bolsa Exterior. 
Em relação à vigência do fomento, registra-se que o maior período de duração foi onze meses. Esse tempo repetiu-se em doze ocasiões, enquanto o menor tempo, é de seis dias, recorrente no caso de professores visitantes na instituição. Já no caso de orientadores, Mayara Rodrigues Gomes foi a professora que mais apareceu orientando pesquisas dez vezes. Também participou de um grande projeto sobre teatro, no qual orientou muitos estudantes da Iniciação Científica. Outros pesquisadores que aparecem nessa condição são: Maria Cristina Castilho Costa, Ciro Marcondes Filho e Ismar de Oliveira Soares, com três projetos de orientação cada, além de Elza Dias Pacheco, Roseli Fígaro, Eduardo Vicente, Eneus Trindade e Marília Pacheco Fiorilho com uma orientação cada.

O levantamento mostrou a concessão de apenas uma bolsa de Mestrado. A pesquisa contemplada trata sobre Publicidade e Comunicação na Infância. Pequena também é a produtividade apontada no Banco de Dados da FAPESP em Doutorado. Foram dois estudos elencados: um sobre poros, ou passagens, da Comunicação e outro sobre Educomunicação e espaços da Educação Formal. Em relação a esses números incipientes, uma hipótese que levantamos é pelo fato da USP ser uma universidade pública, talvez seja menor o interesse em obter recursos da FAPESP, uma vez que o estudante não tem a preocupação pecuniária mensal com a manutenção de seus estudos.

Dos auxílios à pesquisa, a maior busca ocorreu por auxílios temáticos e por recursos para infraestrutura institucional, no caso, laboratórios. Há poucas menções sobre referências bibliográficas. Entretanto percebe-se a valorização de autores latino-americanos e clássicos de outros campos do conhecimento, que não a Comunicação. Aparecem referências a Jacques Rancière (partilha do sensível); Jacques Lacan (rede significante); Michel Foucault (identidade); Pierre Levy (hipertexto); Jesús Martin-Barbero; Francisco Sierra; Guillermo Orozco e Ismar Soares (Comunicação/Educação).

Em relação aos 48 temas identificados, evidenciam a pluralidade de pesquisas no Programa de Pós-Graduação com destaque ao tema da censura no teatro, que propiciou a formação de um grande acervo à instituição. Por se tratar de um período que marca a primeira passagem de século nos estudos comunicacionais, já se percebe a aparição de temas como Internet e Comunicação Digital. Também se mostra muito grande a demanda de pesquisadores que abordam, em suas investigações, a Cultura.

Há alguma procura por programas específicos da FAPESP, porém, irrisória. Dentre os pesquisadores beneficiados, consideramos discentes e docentes, que totalizaram 36 nomes. Faz-se necessário destacar alguns nomes de expressão da Área como Maria Imacolatta Vassalo de Lopes e Margarida 
Kunsch assim como outras acadêmicas reconhecidas, casos de Sandra Reimão e Maria Cristina Castilho Costa.

Percebe-se, ainda no material analisado, o esforço de manter a ECA no cenário internacional pela vinda de pesquisadores estrangeiros. Foram professores pesquisadores a visitá-la: dois da Espanha, dois da Itália, dois da França, um de Portugal e um dos EUA. Nota-se a preferência por pesquisadores europeus, como traço da tradição de uma linha de pensamento mais crítica e menos funcionalista, já presente na gênese da instituição. Esse traço faz que o programa da ECA/USP privilegie o olhar reflexivo sobre o problema de pesquisa. Os pesquisadores visitantes foram: José Maria Gonçalves da Silva Ribeiro (Universidade Aberta Portugal); Patricia Aufderheide (American University, EUA); Nicole dos Santos de Almeida (Universitè Partis-Sorbonne Paris 4, França); Pedro Antonio Hellín Ortuño (Universidad de Murcia, Espanha); Alberto Abruzzese (Libera Universitá de Lingue e Comunicazione, Itália); Vicente Romano García (Universidad de Sevilla, Espanha); Massimo Canevacci (Universitá degli Studi di Roma La Sapienza, Itália); Josep María Catalá Domènech (Universitat Autónoma de Barcelona) e Michel Riaudel (Université de Poitiers, França).

Nos estudos que receberam o apoio da FAPESP, pouco se definem metodologias, porém, as mais recorrentes foram a Pesquisa Bibliográfica e a Análise de Discurso. Por outro lado, existe uma contribuição interessante de pesquisas de Pós-Doc que mostram a preocupação em analisar os processos censórios do arquivo Manoel Silveira, além da preocupação teórica em fundamentar análises sobre os processos digitais emergentes e sobre a multidisciplinaridade nas relações entre Comunicação e Educação.

Ganhou destaque o número de projetos de Iniciação Científica e o de pesquisadores da ECA/USP a pedir bolsa estágio de pesquisa no exterior. Novamente, retirea-se a preferência por instituições europeias haja vista que dos auxílios, dois foram para instituições da França, um para a Itália e um para a Inglaterra. Os pesquisadores saíram do Brasil para ampliar suas pesquisas em livros, televisão e música. Ainda sobre a Iniciação Científica, o tema mais pesquisado foi o poder da fala na cena paulista do teatro.

\section{PESQUISAS NA UNIVERSIDADE METODISTA}

O levantamento junto à Biblioteca Virtual da FAPESP apontou 48 resultados para projetos apoiados pela agência de fomento. Sobre a vigência dos benefícios, a maior duração foi de quarto anos, enquanto a menor foi de um dia. Já no que se refere às orientações, as professoras Anamaria Fadul e Verônica Patrícia A. Cortes aparecem com o maior número delas, cinco cada uma, vinculadas aos projetos de pesquisa FAPESP. Depois aparecem Fábio Josgrilberg, com quatro; Ronaldo Entler, Maria das Graças Caldas, Magali 
do Nascimento Cunha, Walter Lima Jr., José Marques de Melo e Marli dos Santos, com uma cada.

Constam três bolsas de mestrado nesse período. Os temas de pesquisa trabalhados foram Ciência e Pseudociência; Análise do discurso da Revista Veja na construção da realidade dos evangélicos no Brasil e Estratégias de Transmídia no caso da campanha da Fanta. Já entre as pesquisas de doutorado, apareceram o rádio em tempos de Internet e um estudo teórico sobre Folkcomunicação.

Nos Auxílios à Pesquisa, destacou-se a obtenção de fomentos para organizar reuniões científicas: foram quinze concessões da FAPESP. Os segundos pedidos que mais apareceram visaram a publicação de livros e a promoção de pesquisadores visitantes do México e dos EUA. Já entre os beneficiários, apareceram trinta pessoas. Destaque para a Prof ${ }^{a}$ Dra. Cicilia Peruzzo com oito fomentos conquistados. Logo, na sequência, está o Prof. Dr. Fábio Josgrilberg, com cinco apoios. Sobre temas de pesquisa, o mais recorrente é o Jornalismo, com seis menções. Logo depois, aparece a Globalização, com cinco.

Observa-se ainda uma grande produtividade na Iniciação Científica com onze projetos de pesquisa que passam por temas como Globalização Midiática (3 vezes); Novas Tecnologias e Ética em Fotojornalismo; Estudos Comparativos na Grande Imprensa; Jornalismo Local; a Construção Jornalística de uma Ideologia Partidária e o Mercado de Trabalho para a Mulher no Jornalismo. Em relação às metodologias aplicadas, a Pesquisa Qualitativa Descritiva e a Técnica da Entrevista são as que mais aparecem totalizando quatro ocasiões.

Há um grande número de autores citados nas referências bibliográficas. Aparecem: Robertson (Teoria da Glocalização); Nordenstreng \& Varis (Fluxos Midiáticos); Hamelink; Mayo; Browne (Radiodifusão); Sitaram \& Cogdell; Samovar \& Porter (Comunicação Intercultural); Goffman (Manipulação da Imagem Deteriorada); Bakhtin (Gêneros Discursivos); Foucault (Discursos de Verdade); Luiz Beltrão (Folkcomunicação) e outros autores sem a citação do tema trabalhado como Anderson; Bell; Shirky; Guerra e Neves.

O pedido de bolsas no exterior ainda é pequeno. Os dois projetos apresentados visavam diálogos com instituções da França e da Inglaterra. Já o Programa de Capacitação Técnica recebeu grande adesão, em especial, de estudantes que se valeram da bolsa para dedicar-se a um estudo específico sobre infovias municipais no Brasil. 


\section{CONSIDERACÕES FINAIS}

Pode-se dizer que a ECA/USP tem a preocupação de formar o pesquisador desde o estágio inicial haja vista o interesse demonstrado pela Iniciação Científica. Percebe-se, também, que o nível do pesquisador, discente ou docente, não constitui critério para a qualificação, afinal, vemos todas as frentes recorrendo a auxílios, o que mostra o compromisso da Universidade com uma das atividades que sustentam sua gênese: a pesquisa. Também se verifica a importância dada ao diálogo do programa com a comunidade internacional, pois, são consideráveis os pedidos de bolsa para estágio no exterior bem como a solicitação de auxílios para trazer pesquisadores estrangeiros ao convívio acadêmico do seu Programa de Pós-Graduação em Comunicação.

Na Universidade Metodista de São Paulo, percebe-se ainda a valorização da pesquisa, especialmente, na formação do pesquisador uma vez que há considerável adesão de bolsas da Iniciação Científica com temas variados. Nota-se a especificidade maior, em termos de definição e de explicitação das metodologias empregadas, bem como dos referenciais bibliográficos essenciais para o desenvolvimento da pesquisa. Além disso, é nítida a abertura do programa para dialogar, em função das inúmeras solicitações de apoio a reuniões científicas, o que demonstra que a pesquisa não fica intramuros. Inclina-se o referido programa aos estudos que priorizam as questões locais as quais em grande parte, se executam por meio da pesquisa realizada no âmbito do Jornalismo. No quesito internacionalização, há um vínculo muito estreito com o pesquisador mexicano Jorge González, o que ressaltamos como extremamente positivo para o intercâmbio mais concreto.

Portanto, ao comparar os dois programas, podemos identificar uma similaridade, não apenas quantitativa mas também qualitative, no tocante a questões como priorizar a formação do pesquisador e o diálogo de ambos para além de suas fronteiras. Embora as idades se distanciem, fica a impressão de que, em ambas as instituições, existem espíritos científicos capazes de dar à pesquisa uma condição atemporal no ãmbito dos Estudos em Comunicação.

\section{REFERÊNCIAS}

BACHELARD, Gaston. A formação do espírito científico: contribuição para uma psicanálise do conhecimento. Rio de Janeiro: Contraponto, 1996. 316p. Trad. Estela dos Santos Abreu. 6 ed, 1995.

BACHELARD, Gaston. Ensaio sobre o conhecimento aproximado. Rio de Janeiro: Contraponto, 2004. 318p. Trad. Estela dos Santos Abreu.

DILTHEY, Wilhelm. A construção do mundo histórico nas ciências humanas. São Paulo: Editora UNESP, 2010. 346p.. Trad. Marco Casanova.

ESCOLA de Comunicações e Artes Universidade de São Paulo. Disponível em: < $\underline{w w w . e c a . u s p . b r}>$. Acesso em: 10 nov. 2016. 
FUNDAÇÃO de Amparo à Pesquisa do Estado de São Paulo (FAPESP). Disponível em: < wwww.fapesp. br >. Acesso em: 10 nov. 2016.

MARQUES DE MELO, José. O Grupo Comunicacional de São Bernardo: ideias hegemônicas e perfil sociográfico. Revista Brasileira de Ciências da Comunicação. São Paulo: n.1, v. 22, jan-jul 1999. pp. 57-68. MARQUES DE MELO, José. A batalha da comunicação. Sorocaba, SP: EDUNISO, 2008.

MARQUES DE MELO, José. Teoria e Metodologia da Comunicação - tendências do século XXI. São Paulo: Paulus, 2014.

MESTRADO e Doutorado em Comunicação. Disponível em: <www.metodista.br/poscom>. Acesso em: 01 nov. 2016.

RELATÓRIO de Avaliação 2010-2012 Trienal 2013. Disponível em <www.capes.gov.br>. Acesso em: 21 ago. 2014. 